\title{
Testicular shielding in penile brachytherapy
}

\author{
Arpita Bindal, MD', Umesh Mahantshetty, MD, DNB', Chandrashekhar M. Tambe, BSc², Yogesh Ghadi, MSc², Vedang \\ Murthy, MD, DNB!', Shyam Kishore Shrivastava, MD, DNB' \\ 'Department of Radiation Oncology, ${ }^{2}$ Department of Medical Physics, Tata Memorial Hospital, Mumbai, India
}

\begin{abstract}
Purpose: Penile cancer, although rare, is one of the common genitourinary cancers in India affecting mostly aged uncircumcised males. For patients presenting with small superficial lesions $<3 \mathrm{~cm}$ restricted to glans, surgery, radical external radiation or brachytherapy may be offered, the latter being preferred as it allows organ and function preservation. In patients receiving brachytherapy, testicular morbidity is not commonly addressed. With an aim to minimize and document the doses to testis after adequate shielding during radical interstitial brachytherapy for penile cancers, we undertook this study in 2 patients undergoing brachytherapy and forms the basis of this report.

Material and methods: Two patients with early stage penile cancer limited to the glans were treated with radical high-dose-rate (HDR) brachytherapy using interstitial implant. A total of 7-8 tubes were implanted in two planes, parallel to the penile shaft. A total dose of 44-48 Gy (55-60 Gy EQD2 doses with $\alpha / \beta=10)$ was delivered in 11-12 fractions of 4 Gy each delivered twice daily. Lead sheets adding to $11 \mathrm{~mm}(4-5$ half value layer) were interposed between the penile shaft and scrotum. The testicular dose was measured using thermoluminescent dosimeters. For each patient, dosimetry was done for 3 fractions and mean calculated.

Results: The cumulative testicular dose to left and right testis was 31.68 cGy and 42.79 cGy for patient A, and 21.96 cGy and $23.28 \mathrm{cGy}$ for patient B. For the same patients, the mean cumulative dose measured at the posterior aspect of penile shaft was $722.15 \mathrm{cGy}$ and $807.72 \mathrm{cGy}$, amounting to $16.4 \%$ and $16.8 \%$ of the prescribed dose. Hence, the application of lead shield $11 \mathrm{~mm}$ thick reduced testicular dose from 722-808 cGy to 21.96-42.57 cGy, an "absolute reduction" of $95.99 \pm 1.5 \%$.

Conclusions: With the use of a simple lead shield as described, we were able to effectively reduce testicular dose from "spermicidal" range to "oligospermic" range with possible reversibility.

J Contemp Brachytherapy 2015; 7, 6: 503-507 DOI: $10.5114 /$ jcb.2015.56410
\end{abstract}

Key words: HDR brachytherapy, penile brachytherapy, radiation, shielding, testicular cancer.

\section{Purpose}

Penile cancer although rare, is one of the common genitourinary cancers in India affecting mostly aged uncircumcised males with a history of smoking. The age adjusted incidence in rural India is as high as 3 per 100,000 men accounting for more than $6 \%$ of malignancies in this population. Penile cancer is mostly seen involving glans (48\%) and prepuce $(21 \%)$. It may arise from the coronal sulcus in $6 \%$ of the cases and rarely from the shaft $(<2 \%)$ [1]. Since this superficial lesion in early stages seldom interferes with voiding or erectile function, patients tend to delay seeking medical attention until it has progressed with invasion of deeper tissue and caused infection and necrosis.

Patients presenting with an early stage preputial lesion - T1-2, N0 may require only circumcision for treatment. For small superficial lesions $<3 \mathrm{~cm}$ restricted to glans, surgery, radical external radiation or brachytherapy (BT) may be offered, the latter being preferred as it allows organ and function preservation. Radical BT may be mould therapy or interstitial BT (low- or high-dose-rate).
Reported late toxicities following interstitial BT include mainly soft tissue necrosis and urethral meatal stenosis. The testicular morbidity namely reproductive and sexual is also a concern but rarely reported. From the available literature on fractionated radiation delivered to male pelvic region, it has been demonstrated that doses up to 2-3 Gy may result in permanent azoospermia while it takes up to $20 \mathrm{~Gy}$ for affecting testosterone secretion $[2,3]$. However, the effect of BT doses on testicular function has not been adequately described.

With an aim to minimize and document the doses to testis after adequate shielding during high-dose-rate (HDR) radical interstitial BT for penile cancers, we undertook this study in two patients and forms the basis of this report.

\section{Material and methods}

Two patients aged 30 and 51 years with early penile cancer T1/T2 lesion-limited to the glans were treated with radical HDR ${ }^{192}$ Ir BT using interstitial implant.

\footnotetext{
Address for correspondence: Prof. Umesh Mahantshetty, MD, DNB, Department of Radiation Oncology, Tata Memorial Hospital, Mumbai - 400012, India, phone: +91 22 24177168, fax: +91 22 24146747, 


\section{Implant technique}

A total of 7-8 tubes were implanted in two planes, parallel to the penile shaft. American Brachytherapy Society (ABS) and Groupe Européen de Curiethérapie of the European Society for Radiotherapy and Oncology (GEC-ESTRO) [4] recommend a template based multiplanar implant with the needles placed orthogonally to the longitudinal direction of the penis. However, we prefer non template based insertion of tubes along the longitudinal direction of the penis with adequate lateral margin, hence, avoiding the soft tissue injury caused due to template and needles being in situ for a long time, generally between 5 to 7 days. Freehand insertion has another advantage of maintained target position relative to the tubes as the post procedure edema settles. Two planes, deep and superficial, sufficiently cover the tumor thickness with margin while restricting doses to the urethra. Brachytherapy treatment planning was done on Oncentra TPS and treatment delivered with MHDR V3 remote afterloading system (Nucletron, an Elekta company, Elekta AB, Stockholm, Sweden). A total dose of 44-48 Gy was delivered in 11-12 fractions of 4 Gy each delivered twice daily, which is higher than recommended by Crook et al. 38.4 Gy at 3.2 Gy per fraction, twice daily 6 hours apart over 6 days [4], but well tolerated in our patient population.

Owing to the proximity of the implant to testes, an attempt was made to minimize the scattered dose to this organ by interposing a lead shield between the penile shaft and scrotum.

\section{Shield design}

The shield was made of lead sheets $14 \mathrm{~cm}$ in length and $6.5 \mathrm{~cm}$ in width. The cumulative thickness was $1.1 \mathrm{~cm}$, approximately equivalent to $4-5$ half value layer (HVL) for ${ }^{192}$ Ir.

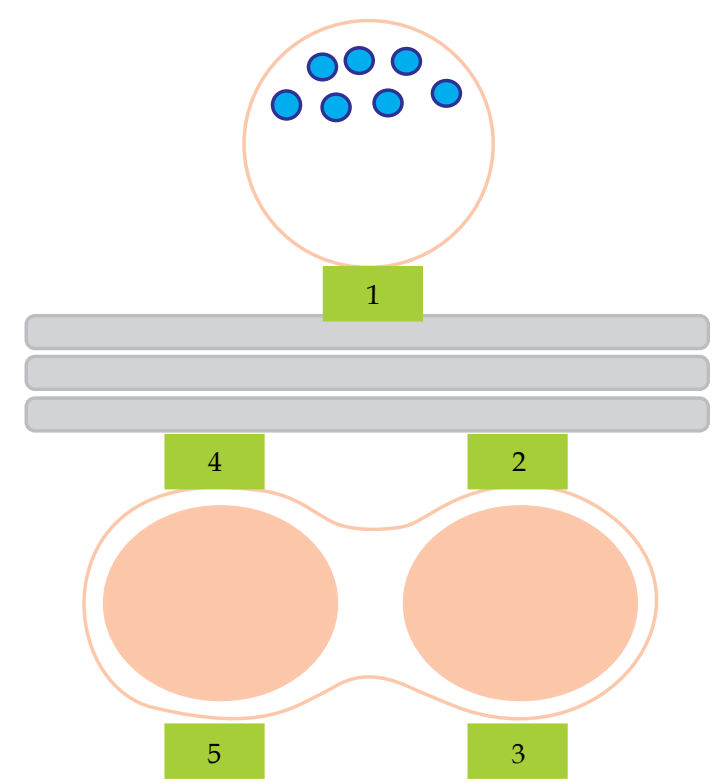

Fig. 1. Schematic representation of thermoluminescent dosimeters placement

\section{Dose measurement}

The testicular dose was measured using $\mathrm{LiF}$ thermoluminescent dosimeters (TLD), a $1 \mathrm{~cm} \times 1 \mathrm{~cm}$ polyethylene pouch consisting of approximately $40 \mathrm{mg}$ of TLD-100 (LiF: Mg, Ti) powder (The Harshaw Chemical Co. Solon, Ohio, USA) in it, so that at least three readings could be procured from it. Prior to each irradiation, the TLD powder was annealed using thermal cycle $400^{\circ} \mathrm{C}\left( \pm 5^{\circ} \mathrm{C}\right)$ for $1 \mathrm{~h}$, cooling for $5 \mathrm{~min}$ and $100^{\circ} \mathrm{C}$ for $2 \mathrm{~h}$ in Programmable Muffle Furnace (Model-126, Fisher Scientific Co, Pittsburgh, USA), and then cooled to room temperature.

\section{Placement of thermoluminescent dosimeters}

Testes were palpated and the first set of TLDs placed on the anterior scrotal skin on either side immediately anterior to the center of the testes (entry dose). Similarly, the second set were placed immediately posterior to the testes (exit dose). The average of the two value sets was a fair estimate of the dose received by the testes. The lead shield was then placed over the scrotum and a TLD placed in the center over the shield, facing the posterior aspect of shaft. This would act as a surrogate for the testicular dose received in the absence of shielding. These 5 measurements were carried out for 3 fractions for each patient and mean values computed (Figures 1 and 2).

\section{Measuring absorbed dose}

A constant time gap of $24 \mathrm{~h}$ was maintained between irradiation and readout. Rexon UL-320 TLD Reader (TLD systems Inc., USA) was used to record TL output at maximum acquisition temperature of $280^{\circ} \mathrm{C}$ using constant heating rate of $14^{\circ} \mathrm{C} / \mathrm{sec}$. For each readout, $10 \mathrm{mg}$ powder was used. Hence, 4 readings were obtained from each TLD pouch and the mean value of net TL output per unit weight of these readings was used for calculation of absorbed dose.

\section{Calibration of thermoluminescent dosimeters}

Dose response curve for the TLD-100 powder was generated in ${ }^{60} \mathrm{Co}$ gamma ray beam (Equinox 80, MDS Nordion, Canada). Irradiation was performed in a virtual water phantom and the measuring point had at least $10 \mathrm{~cm}$ of scatter material on all sides to provide full scattering condition.

\section{Phantom dosimetry}

To measure the efficacy of the shield in reducing testicular dose, a wax phantom of size $3 \times 3 \mathrm{~cm}$ with separation $4 \mathrm{~cm}$ was used. The source was positioned on the anterior side and irradiated for 2 minutes with single dwell position. The TLDs were placed on the posterior aspect, just below the source and above the first lead sheet. The lead sheets were arranged, one below the other, and TLDs placed below each sheet subsequently to measure their individual attenuation. This simulated the treatment situation. The measured dose was plotted against the lead thickness to study the dose attenuation 


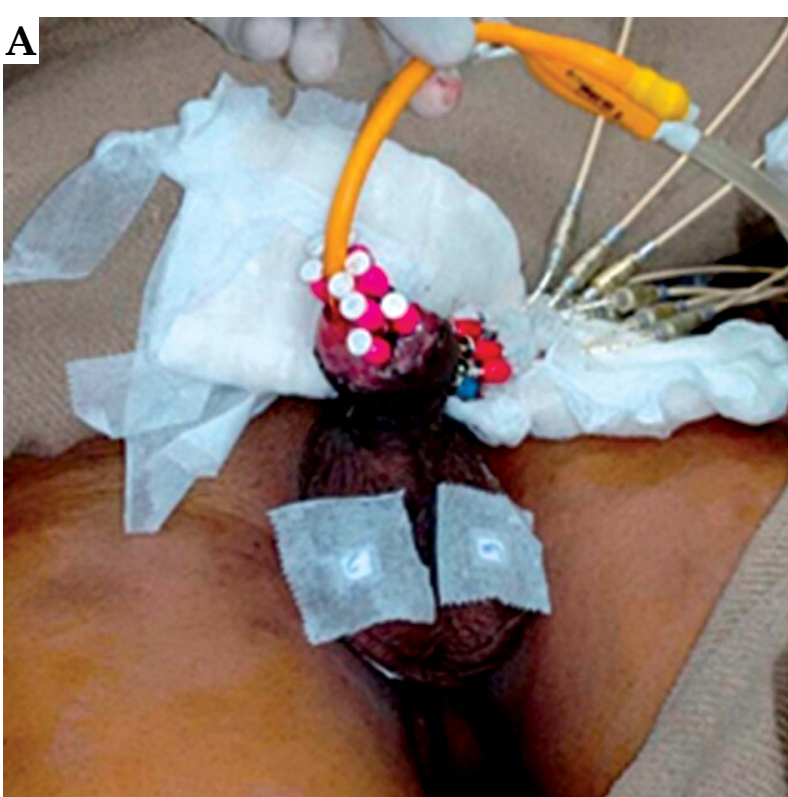

Fig. 2. Patient A without (A) and with (B) lead shield in place

and determine half value thickness (HVT) for mHDR ${ }^{192}$ Ir source.

\section{Results}

As detailed in material and methods, two patients underwent TLD measurements for 3 fractions of HDR and extrapolated to the remaining fractions.

\section{Testicular doses (see Table 1)}

Patient A: A total of $44 \mathrm{~Gy}$ in 11 fractions was delivered at 4 Gy per fraction, twice daily $6 \mathrm{~h}$ apart. The dose to left and right testes was $2.88 \pm 0.10 \mathrm{cGy}$ and 3.89 $\pm 0.74 \mathrm{cGy}$, respectively, resulting in a cumulative dose of $31.68 \pm 1.10$ cGy and $42.79 \pm 8.14$ cGy.

Patient B: A total of 48 Gy in 12 fractions was delivered at 4 Gy per fraction, twice daily $6 \mathrm{~h}$ apart. The dose to left and right testes was $1.83 \pm 0.40 \mathrm{cGy}$ and 1.94

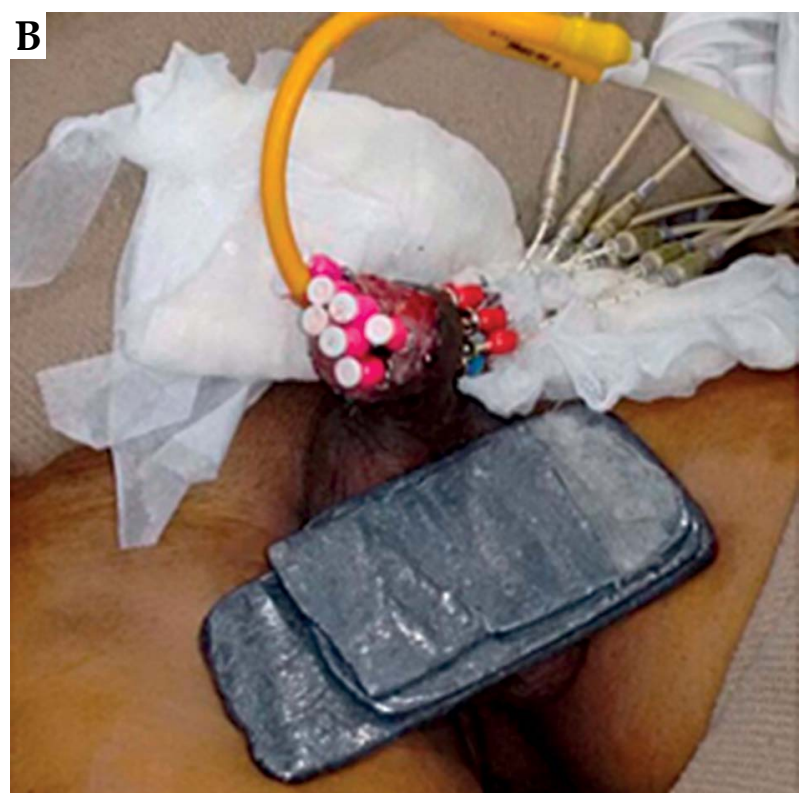

\pm 0.07 cGy, respectively, resulting in a cumulative dose of $21.96 \pm 4.80 \mathrm{cGy}$ and $23.28 \pm 0.84 \mathrm{cGy}$.

\section{Effect of shielding on dose to the testis}

The mean dose measured at the posterior aspect of penile shaft was $65.65 \pm 6.1 \mathrm{cGy}$ and $67.3 \pm 5.6 \mathrm{cGy}$ for the two patients, amounting to $16.4 \%$ and $16.8 \%$ of the total delivered dose. This dose being a surrogate for the "unshielded" testicular dose, one can safely assume that unshielded, the cumulative testicular dose would be $722.15 \pm 67.1 \mathrm{cGy}$ and $807.72 \pm 67.44 \mathrm{cGy}$ for two patients, respectively.

Hence, the application of lead shield $1.1 \mathrm{~cm}$ thick reduced testicular dose from 722-808 cGy to 21.96-42.57 cGy, an "absolute reduction" of $95.99 \pm 1.5 \%$.

\section{Computing the half value thickness}

The measured HVT for mHDR ${ }^{192}$ Ir source using phantom dosimetry was found to be $2.8 \mathrm{~mm}$ of lead,

Table 1. Actual thermoluminescent dosimeters readings and calculated parameters obtained for the two patients

\begin{tabular}{lcccccccccccc} 
& \multicolumn{4}{c}{} & \multicolumn{4}{c}{ Patient A (D=4400 cGy/11\#) } & \multicolumn{4}{c}{ Patient B (D=4800 cGy/12\#) } \\
\cline { 2 - 12 } & R1 & R2 & R3 & Mean & SD & Total (in cGy) & R1 & R2 & R3 & Mean & SD & Total (in cGy) \\
\hline Penis Post & 64.2 & 72.34 & 60.4 & 65.65 & 6.10 & $722.15 \pm 67.10$ & 73.3 & 62.14 & 66.50 & 67.31 & 5.62 & $807.72 \pm 67.44$ \\
\hline Lt Ant & 3.44 & 3.69 & 3.10 & 3.41 & 0.29 & $37.51 \pm 3.19$ & 2.84 & 1.61 & 2.25 & 2.23 & 0.61 & $26.76 \pm 7.32$ \\
\hline Lt Post & 2.19 & 1.96 & 2.90 & 2.35 & 0.49 & $25.85 \pm 5.39$ & 1.45 & 1.14 & 1.67 & 1.42 & 0.26 & $17.04 \pm 3.12$ \\
\hline Lt Mid Calc & 2.82 & 2.83 & 3.00 & 2.88 & 0.10 & $31.68 \pm 1.10$ & 2.15 & 1.38 & 1.96 & 1.83 & 0.40 & $21.96 \pm 4.80$ \\
\hline Rt Ant & 6.64 & 3.74 & 4.90 & 5.09 & 1.45 & $55.99 \pm 15.95$ & 2.57 & 2.29 & 2.17 & 2.34 & 0.20 & $28.08 \pm 2.40$ \\
\hline Rt Post & 2.45 & 2.41 & 3.20 & 2.69 & 0.44 & $29.59 \pm 4.84$ & 1.42 & 1.65 & 1.55 & 1.54 & 0.11 & $18.48 \pm 1.32$ \\
\hline Rt Mid Calc & 4.55 & 3.08 & 4.05 & 3.89 & 0.74 & $42.79 \pm 8.14$ & 2.00 & 1.97 & 1.86 & 1.94 & 0.07 & $23.28 \pm 0.84$
\end{tabular}

Readings R1, R2, and R3 obtained on TLD 1 (Penis Post; ventral surface of penile shaft), TLD 2 (Lt Ant; anterior surface of left testis), TLD 3 (Lt Post; posterior surface of left testis), TLD 4 (Rt Ant; anterior surface of right testes), and TLD 5 (Rt Post; posterior surface of right testes). Lt Mid Calc and Rt Mid Calc denote calculated mean of the doses to the anterior and posterior surfaces of the left and right testes, respectively, as measured in 3 fractions. 
Table 2. Dosimetric uncertainties for ${ }^{192} \mathrm{Ir}$ brachytherapy source

\begin{tabular}{|c|c|c|}
\hline Source of uncertainty & Value & Reference \\
\hline Air Kerma Strength measurement & $1.5 \%$ & [16] \\
\hline Source to TLD positioning & $<3 \%$ & [18] \\
\hline TLD calibration using ${ }^{60} \mathrm{Co}$ & $3 \%$ & [19] \\
\hline Temporal fading & Negligible & All readouts were done at $24 \mathrm{~h}$ from irradiation \\
\hline TLD readout uncertainties & $2 \%$ & $\begin{array}{l}\text { Including PMT linearity correction, reader stability, and TLD reproducibility } \\
\text { (institutional data) }\end{array}$ \\
\hline Type A uncertainties & $<3 \%$ & \\
\hline Total dosimetric uncertainty & $6 \%$ & Coverage factor $[\mathrm{k}]=1$ \\
\hline
\end{tabular}

PMT - photomultiplier tube, TLD - thermoluminescent dosimeter

which is in accordance with the published data of 2.1 to $2.8 \mathrm{~mm}$ [5]. The reported TVL value for ${ }^{192} \mathrm{Ir}$ ranges from 9.2 to $11.9 \mathrm{~mm}$ of lead [5].

\section{Discussion}

Radical BT is a viable option for penile preservation in selected patients with T1-T2 lesions $<4 \mathrm{~cm}$ in diameter [6]. Results of BT for penile carcinoma are most often reported in the form of institutional case series $[7,8,9$, 10, 11]. A meta-analysis by Hasan et al. of 17 such studies reports 5 year overall survival of $73 \%, 5$ year local control of $79 \%$ with an organ preservation rate of $74 \%$ in a cohort of 673 patients. Although penectomy provides better control, there is no survival benefit, implying that in most cases salvage surgery is a feasible option in case of recurrence [12].

Nearly $20-30 \%$ of patients develop side effects, such as telangiectasia, depigmentation, fibrosis, sclerosis, and less frequently urethral stenosis and necrosis. Besides the urethra, it is also important to minimize the doses to testes. Testes are very sensitive to radiation and side effects are dose dependent. Literature reports many adverse effects of scattered dose to testis, including oligospermia, azoospermia, temporary or permanent, testicular atrophy, Leydig cell dysfunction with impairment of testosterone production, and genetic risk of hereditary disease or developmental impairment of the offspring of irradiated patients [3, 13, 14, 15, 16]. Howell et al. in 2005 reported the effect of cancer therapy on spermatogenesis. Elaborating on radiation sensitivity of testes, they reported that with fractionated delivery, doses of 70-90 cGy result in oligospermia with recovery at 1-1.5 years. Single fraction spermicidal doses are 0.1-0.2 Gy for spermatogonia, 2-3 Gy for spermatocytes and 4-6 Gy for spermatids. With doses of 6-8 Gy the spermicidal effect is permanent, resulting in permanent azoospermia [3]. So, minimizing doses to testes during HDR BT for penis becomes important. Equally important would be to measure and document the doses during treatment and systematically correlate these with toxicities.

In the present study, we attempted to define two issues. Firstly, we utilized the lead shielding to minimize the doses to testes. Secondly, radiation dose measure- ments by using TLD at anterior and posterior surface of the scrotum were done to compute testicular doses. With the use of a simple lead shield as described, we were able to effectively reduce testicular dose from "spermicidal" (6-8 Gy) range to "oligospermic" (<0.7 Gy) range with possible reversibility [3]. The backscatter from lead shield is estimated to increase the measured dose at posterior shaft by about $1-2 \%$ [17], hence the actual dose at that point in the absence of lead shield would be about 707791 cGy.

The advantage of TLD is its linearity of response to dose, relative energy independence, and sensitivity to low doses. Their small size makes measurement of point dose feasible. DeWerd et al. [18] and Kirisits et al. [19] have published reports emphasizing the need to address the dosimetric uncertainties in brachytherapy, hence, this discussion would be incomplete without addressing this issue (Table 2). Taking the dosimetric uncertainties into account, the upper limit of dose received by the testes would be about $46 \mathrm{cGy}$, in the presence of shielding.

\section{Conclusions}

Use of testicular shield during HDR BT for penile cancers reduces doses to testes. Direct measurements of doses to testes using TLD during high-dose-rate BT for penile cancers allows for objective documentation, which could be helpful for better correlation with late toxicities.

\section{Disclosure}

Authors report no conflict of interest.

\section{References}

1. Misra S, Chaturvedi A, Misra NC. Penile carcinoma: A challenge for the developing world. Lancet Oncol 2004; 5: 240-247.

2. Trottmann M, Becker AJ, Stadler T et al. Semen quality in men with malignant diseases before and after therapy and the role of cryopreservation. Eur Urol 2007; 52: 355-367.

3. Howell SJ, Shalet SM. Spermatogenesis after cancer treatment: damage and recovery. J Natl Cancer Inst Monogr 2005; 34: $12-17$.

4. Crook JM, Haie-Meder C, Demanes DJ et al. American Brachytherapy Society-Groupe Européen de Curiethérapie-European Society of Therapeutic Radiation Oncology (ABS-GEC- 
ESTRO) consensus statement for penile brachytherapy. Brachytherapy 2013; 12: 191-198.

5. Mondat M, Blais N, Wierzbicki W. Evaluation of the tenth value layer (TVL) and half value layer (HVL) in lead for the primary and the scattered radiation of an iridium 192 (Ir-192) source-Facility design. Med Phys 2002; 1234.

6. Hakenberg OW, Compérat E, Minhas $\mathrm{S}$ et al. Guidelines on Penile Cancer. European Association of Urology 2015.

7. Crook JM, Jezioranski J, Grimard L et al. Penile brachytherapy: Results for 49 patients. Int J Radiat Oncol Biol Phys 2005; 62: 460-467.

8. Chaudhary AJ, Ghosh S, Bhalavat RL et al. Interstitial brachytherapy in carcinoma of the penis. Strahlenther Onkol 1999; 175: 17-20.

9. Kiltie AE, Elwell C, Close HJ, Ash DV. Iridium-192 Implantation for node-negative carcinoma of the penis : the Cookridge Hospital experience. Clin Oncol (R Coll Radiol) 2000; 12: 25-31.

10. de Crevoisier R, Slimane K, Sanfilippo N et al. Long-term results of brachytherapy for carcinoma of the penis confined to the glans (N- or NX). Int J Radiat Oncol Biol Phys 2009; 74: 1150-1156.

11. Pimenta A, Gutierrez C, Mosquera D et al. Penile brachytherapy-retrospective review of a single institution. Brachytherapy 2015; 14: 525-530.

12. Hasan S, Traughber B, Kaminsky DA et al. The role of brachytherapy in organ preservation for penile cancer: a meta-analysis and systematic review of the literature. Brachytherapy 2014; 13: S22.

13. Champetier C, Gross E, Pointreau Y et al. Normal tissue tolerance to external beam radiation therapy: testicles. Cancer Radiother 2010; 14: 376-378.

14. Kinsella TJ, Trivette G, Rowland J et al. Long-term follow-up of testicular function following radiation therapy for early-stage Hodgkin's disease. J Clin Oncol 1989; 7: 718-724.

15. Sklar CA, Robison LL, Nesbit ME et al. Effects of radiation on testicular function in long-term survivors of childhood acute lymphoblastic leukemia: a report from the Children Cancer Study Group. J Clin Oncol 1990; 8: 1981-1987.

16. Magelssen H, Brydøy M, Fosså SD. The effects of cancer and cancer treatments on male reproductive function. Nat Clin Pract Urol 2006; 3: 312-322.

17. Candela-Juan C, Granero D, Vijande J et al. Dosimetric perturbations of a lead shield for surface and interstitial highdose-rate brachytherapy. J Radiol Prot 2014; 34: 297-311.

18. DeWerd LA, Ibbott GS, Meigooni AS et al. A dosimetric uncertainty analysis for photon-emitting brachytherapy sources: Report of AAPM Task Group No. 138 and GEC-ESTRO. Med Phys 2011; 38: 782-801.

19. Kirisits C, Rivard MJ, Baltas D et al. Review of clinical brachytherapy uncertainties: analysis guidelines of GECESTRO and the AAPM. Radiother Oncol 2014; 110: 199-212. 